\title{
Effects of glycerol concentration on the motility of equine spermatozoa after thawing
}

\author{
Miroslava Mráčková1, Eliška Horáčková ${ }^{1}$, Michal Vyvial ${ }^{1}$, Antonín Vinkler ${ }^{1}$, \\ Šárka Krisová ${ }^{1}$, Štěpán Bodeček ${ }^{1}$, Markéta Sedlinská ${ }^{1}$ \\ ${ }^{1}$ University of Veterinary and Pharmaceutical Sciences Brno, \\ Faculty of Veterinary Medicine, Equine Clinic, Brno, Czech Republic \\ Received January 26, 2017 \\ Accepted October 2, 2017
}

\begin{abstract}
The aim of this study was to evaluate the effect of different glycerol concentrations on stallion sperm motility after thawing. For statistical analysis 228 ejaculates were used. The semen was filtrated to remove gel fraction; macroscopic and microscopic evaluation was done. After evaluation the ejaculates were centrifuged, the supernatant was removed and the spermatozoa were re-suspended in French diluent with different concentrations of glycerol $(2.0 ; 2.5 ; 4.0$ and $6.0 \%$ ). The choice of concentration of glycerol for a particular ejaculate was completely random. The spermatozoa were packed into $0.5 \mathrm{ml}$ straws and placed for $2 \mathrm{~h}$ in a fridge $\left(4^{\circ} \mathrm{C}\right)$. Then the straws were placed in liquid nitrogen vapor $\left(-80\right.$ to $\left.-100^{\circ} \mathrm{C}\right)$ and after 10 min plunged into liquid nitrogen and stored at $-196{ }^{\circ} \mathrm{C}$ for at least $48 \mathrm{~h}$. The selected straws were individually thawed in a $38^{\circ} \mathrm{C}$ water bath for $30 \mathrm{~s}$ prior to post-freezing analysis. Two progressive motilities using phase contrast microscopy (magnification $\times 400$ ) were recorded: motility II immediately after thawing and motility III after $2 \mathrm{~h}$ incubation in a $38{ }^{\circ} \mathrm{C}$ water bath. The Spearmen/Kendall rang correlation test was selected to prove whether there is a correlation between the selected indices (glycerol concentration and motility II and motility III). Nonparametric multiple group analysis (Steel-Dwass test) was applied for finding the differences between groups. The Spearman/Kendall rang correlation proved a relationship between motility II and glycerol concentration. It can be stated that in this study the best glycerol concentration for freezing equine spermatozoa is with a concentration of $4.0 \%$ glycerol.
\end{abstract}

Cryopreservation, stallion, ejaculate

Cryopreservation of sperm is of great importance for the equine breeding industry since it allows for long-term storage and transportation (Hoffmann et al. 2011). Glycerol was used successfully as the first cryoprotectant for spermatozoa (Polge et al. 1949) and the first pregnancy using frozen semen was reported by Baker and Gandier (1957). The effect of glycerol is not only protective but also toxic (Marcias Garcia et al. 2012) and this could be a cause for the variation of stallion sperm motility after thawing (Alvarenga et al. 2005). Contraceptive effects of glycerol in mares has also been published (Demick et al. 1976). There are a number of works dealing with the search for alternative cryoprotectants not only for stallion ejaculate, but also for the cryopreservation of sperm in other animal species and humans (Futino et al. 2010; Swelum et al. 2011). Investigated substances are specifically compounds of glycol: ethylene glycol, propylene glycol, diethylene glycol, dimethyl sulphoxide (Chenier et al. 1998; Moore et al. 2006; Hoffmann et al. 2010) or various amides: formamide, methylformamide, dimethylformamide, acetamide or methylacetamide (Gomes et al. 2002; Vidament et al. 2002; Squires et al. 2004; Alvarenga et al. 2005; Ferreira et al. 2008). Some of these alternative cryoprotectives are combined with glycerol and varying concentrations of each cryoprotective both individually and in combination have been described (Vidament et al. 2002; Melo et al. 2007; Pucci et al. 2008; Hoffmann et al. 2011; Alvarez et al. 2014; Wu et al. 2015; Moffett et al. 2016).

Address for correspondence:

MVDr. Markéta Sedlinská, Ph.D.

Equine Clinic, Faculty of Veterinary Medicine

University of Veterinary and Pharmaceutical Sciences Brno

Palackého tř. 1946/1, 612 42, Brno, Czech Republic 
Despite all the investigations so far, none of the above mentioned substances have significantly improved the effects of cryoprotectants than glycerol and therefore glycerol, even with its toxic effects, is still widely used for freezing stallion ejaculates (Ball and Vo 2001; Marcias Garcia et al. 2012), or the sperm of other kinds of animals, and even other types of cells (Woods et al. 2004; Mazur et al. 2008).

The optimal concentration of glycerol in extenders is still not clear and published studies differ a great deal (Cochran et al. 1984; Burns and Reasner 1995; Vidament et al. 2001; Fayrer-Hosken et al. 2008; Hoffmann et al. 2011; Wu et al. 2015). But even so it remains an essential cryoprotectant (at concentrations of 2.5-6.0\%) in almost all conventional extenders used for freezing stallion spermatozoa (Vidament et al. 2001). This study aims to shed light on the importance of glycerol concentration on the motility of equine spermatozoa after thawing.

\section{Materials and Methods}

Semen used for the experiment in this study was collected from 49 stallions of different breeds (21 warmblood stallions, 18 Old Kladruber stallions, 7 draught horses, 2 Haflingers and 1 thoroughbred stallion) kept at five different stud farms. The stallions' ages ranged from 3 to 18 years and all of them were actively used in breeding. All doses were prepared for commercial use in artificial insemination.

In total 278 ejaculates were collected using the Missouri model of artificial vagina, (1-10 from each stallion). After collection, the semen was filtrated to remove gel fraction; macroscopic and microscopic evaluation was done. Only those ejaculates which, at the first evaluation, had a beginning progressive motility higher than $60 \%$ (motility I) were selected for freezing. Actually 228 ejaculates were used for statistical analysis. After evaluation the ejaculates were centrifuged $(1000 \mathrm{~g}, 10 \mathrm{~min})$, the supernatant was removed and the spermatozoa were re-suspended in the French diluent (own preparation) (Palmer 1984) supplemented with $2 \%$ of centrifuged egg yolk (own preparation) and with different concentrations of glycerol $(2.0 ; 2.5 ; 4.0$ and $6.0 \%)$. The choice of concentration of glycerol for a particular ejaculate was completely random. The spermatozoa were packed into $0.5 \mathrm{ml}$ straws and placed in the fridge for $2 \mathrm{~h}\left(4^{\circ} \mathrm{C}\right)$. Then the straws were placed in liquid nitrogen vapor $\left(-80\right.$ to $\left.-100{ }^{\circ} \mathrm{C}\right)$ and after $10 \mathrm{~min}$ plunged into liquid nitrogen and stored at $-196{ }^{\circ} \mathrm{C}$ for at least $48 \mathrm{~h}$.

The selected straws were individually thawed in a $38^{\circ} \mathrm{C}$ water bath for $30 \mathrm{~s}$ prior to post-freezing analysis. Two progressive motilities using phase contrast microscopy (magnification $\times 400$ ) were recorded: motility II immediately after thawing and motility III after $2 \mathrm{~h}$ incubation in a $38^{\circ} \mathrm{C}$ water bath.

Based on the glycerol concentration used, ejaculates were divided into 4 groups: A, B, C, D.

- Group A (84 ejaculates):

Concentration of glycerol in diluent $2.0 \%$

- Group B (58 ejaculates):

Concentration of glycerol in diluent $2.5 \%$

- Group C (69 ejaculates):

Concentration of glycerol in diluent $4.0 \%$

- Group D (16 ejaculates):

Concentration of glycerol in diluent $6.0 \%$

Because of the large variance of obtained results in each group, nonparametric methods for statistical analysis were used. The Spearman and Kendall rank correlation test was selected to prove whether there is a correlation between the selected indicators (glycerol concentration and motility II and motility III). Nonparametric multiple group analysis (Steel-Dwass test) was applied for the analysis of the differences between groups.

\section{Results}

The Spearman and Kendall rank correlation test demonstrated a strong relationship $(P \leq 0.001)$ between glycerol concentration and sperm progressive motility immediately after thawing (motility II). No relationship was found between glycerol concentration and sperm progressive motility after $2 \mathrm{~h}$ of incubation after thawing (motility III) $(P>0.05)$ (Table 1).

After statistical evaluation of all four groups using Steel-Dwass test (Table 2) it is evident that the highest sperm progressive motility immediately after thawing was found in group $\mathrm{C}(P \leq 0.01)$. Group $\mathrm{C}$ is the group with $4.0 \%$ of glycerol in French diluent (Fig. 1). Because the Spearman and Kendall rank correlation proved a relationship between these 
Table 1. Correlation coefficient based on dependence of motility II and motility III on glycerol concentration (motility II - sperm progressive motility after thawing, motility III - sperm progressive motility $2 \mathrm{~h}$ after thawing).

\begin{tabular}{lcc}
\hline & $\begin{array}{c}\text { Dependence of motility II } \\
\text { on glycerol concentration }\end{array}$ & $\begin{array}{c}\text { Dependence of motility III } \\
\text { on glycerol concentration }\end{array}$ \\
\hline Spearman's rank correlation coefficient rho & $0.245955^{* * *}$ & 0.078014 \\
Kendall coefficient tau & $0.196264^{* * *}$ & 0.060897 \\
\hline
\end{tabular}

${ }^{* * * *} P \leq 0.001$

Table 2. Coefficients of Steel-Dwass test in the relationship between motility II and glycerol concentration.

\begin{tabular}{|c|c|c|c|c|}
\hline & $\begin{array}{c}\text { Group A } \\
2.0 \% \text { glycerol }\end{array}$ & $\begin{array}{c}\text { Group B } \\
2.5 \% \text { glycerol }\end{array}$ & $\begin{array}{c}\text { Group C } \\
4.0 \% \text { glycerol }\end{array}$ & $\begin{array}{c}\text { Group D } \\
6.0 \% \text { glycerol }\end{array}$ \\
\hline $\begin{array}{l}\text { Group A } \\
2.0 \% \text { glycerol }\end{array}$ & & 0.685235422 & $-4.280937191^{* * * *}$ & 0.512566924 \\
\hline $\begin{array}{l}\text { Group B } \\
2.5 \% \text { glycerol }\end{array}$ & 0.884908805 & & $-4.645587407^{* * *}$ & 0.074468672 \\
\hline $\begin{array}{l}\text { Group C } \\
4.0 \% \text { glycerol }\end{array}$ & 0.000099332 & 0.000018680 & & $3.18045247^{* * *}$ \\
\hline $\begin{array}{l}\text { Group D } \\
6.0 \% \text { glycerol }\end{array}$ & 0.947069589 & 0.999816612 & 0.006981321 & \\
\hline
\end{tabular}

${ }^{* * *} P \leq 0.001 ;{ }^{* *} P \leq 0.01$

two indicators (motility II and glycerol concentration), it can be stated that in this study, the best glycerol concentration for freezing stallion spermatozoa was found to be at a $4.0 \%$.

Group D, the group with $6.0 \%$ of glycerol, had the highest progressive motility two hours after thawing $(P \leq 0.01)$ (Table 3, Fig. 1). No significant relationship was found between motility III and glycerol concentration.

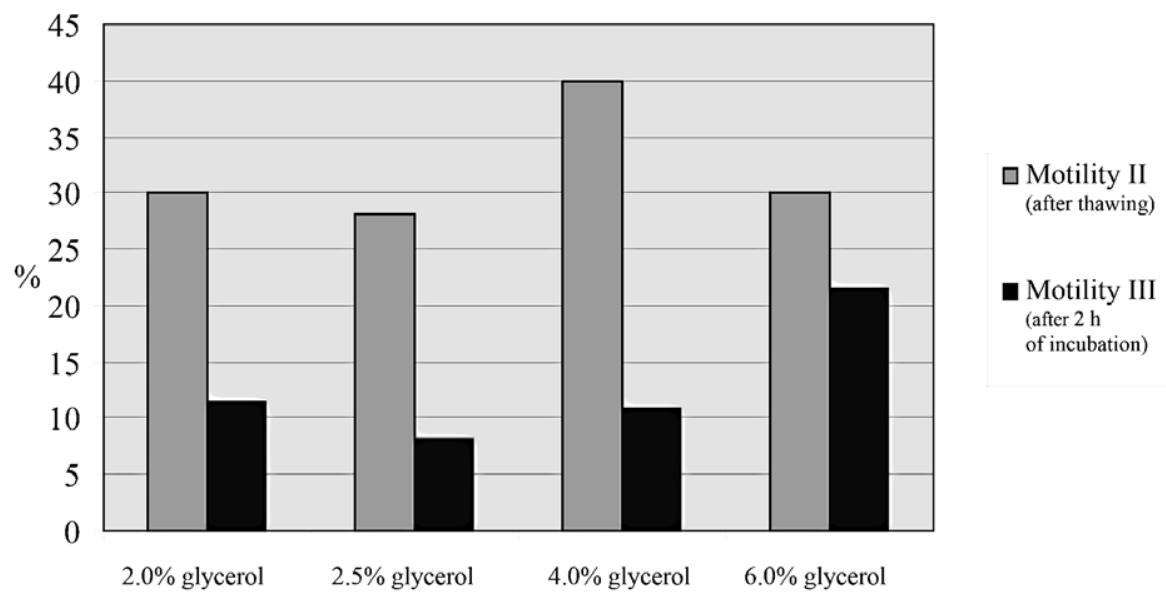

Fig. 1. The average motility according to the amount of glycerol in the diluent 
Table 3. Coefficients of Steel-Dwass test in the relationship between motility III and glycerol concentration.

\begin{tabular}{|c|c|c|c|c|}
\hline & $\begin{array}{c}\text { Group A } \\
2.0 \% \text { glycerol }\end{array}$ & $\begin{array}{c}\text { Group B } \\
2.5 \% \text { glycerol }\end{array}$ & $\begin{array}{c}\text { Group C } \\
4.0 \% \text { glycerol }\end{array}$ & $\begin{array}{c}\text { Group D } \\
6.0 \% \text { glycerol }\end{array}$ \\
\hline \multicolumn{5}{|l|}{ Group A } \\
\hline $\begin{array}{l}2.0 \% \text { glycerol } \\
\text { Group B }\end{array}$ & & 2.06424411 & 0.74798051 & $-3.59221^{* *}$ \\
\hline $\begin{array}{l}2.5 \% \text { glycerol } \\
\text { Group C }\end{array}$ & 0.14464106 & & -1.2232785 & $-4.510359^{* * *}$ \\
\hline $\begin{array}{l}4.0 \% \text { glycerol } \\
\text { Group D }\end{array}$ & 0.85617344 & 0.571413686 & & $-3.648874^{* *}$ \\
\hline $6.0 \%$ glycerol & 0.00164161 & 0.000035196 & 0.00132699 & \\
\hline
\end{tabular}

${ }^{* * *} P \leq 0.001 ;{ }^{* *} P \leq 0.01$

\section{Discussion}

Sperm motility evaluation is a basic assessment of the insemination dose, and under field conditions, the only one which is usually done to prove the usability of the insemination dose. The evaluation of this indicator therefore played an essential role in our study. The sperm motility after thawing is influenced by many factors, including glycerol concentration. The usual concentration of glycerol for freezing the stallion ejaculate is in the range of 2.5-6.0\% (Vidament et al. 2002), but the reported optimal concentration of glycerol differs somewhat in published studies. In our study, we have proved the most suitable concentration at $4.0 \%$ glycerol $(P \leq 0.01)$. Glycerol concentration in the diluent had a clear, highly significant effect $(P \leq 0.001)$ on sperm motility after thawing, which is in agreement with the study of Cochran et al. (1984), who found the $4.0 \%$ concentration to be better for freezing than $2.0 \%$ or $6.0 \%$. A study by Wu et al. (2015) showed a similar result without differences between $3.5 \%$ and $5.0 \%$, but both concentrations were better than the $2.5 \%$ concentration of glycerol. On the contrary, Burns and Reasner (1995) concluded that the optimal concentration of glycerol relative to sperm motility after thawing was only $2.0 \%$. Similarly, Vidament et al. (2001) reported the best concentration of glycerol in the range of 2.4 to $2.8 \%$, although without significance $(P>0.5)$. The observed range was from 1.7 to $3.7 \%$. The same optimal concentration was also recorded by Hoffmann et al. (2011) when a comparison of 1.0-4.0\% glycerol showed that the optimum concentration in their study was $2.0-3.0 \%$. A further study by Vidament et al. (2002), where the effect of glycerol, dimethyl formamide (DMF) and their combinations were evaluated, reported that the highest sperm motility after thawing was achieved at $3.0 \%$ glycerol, compared with $1.0 \%, 2.0 \%$, or a combination of glycerol with DMF or DMF alone. Fayrer-Hosken et al. (2008) reported better motility using $6.0 \%$ concentration of glycerol compared to $3.5 \%$. From all the above mentioned studies, this one included, it is evident that it is very difficult to determine an optimal concentration of glycerol.

In the other studies, ejaculates from several animals were used repeatedly with various concentrations of glycerol, and subsequently, the same ejaculate was compared after thawing, which could explain the differences compared to our results. Another factors are the components of the diluents used, which vary across the studies as each team usually prefers to work with a diluent which is normally used at that particular workplace. Consequently, it is possible and even probable that the optimal concentration of glycerol for each type of diluent may vary, especially when a combination of cryoprotectants is used. 
Even more complicated is the assessment of motility after incubation for a certain period of time after thawing. In our study, the best motility after $120 \mathrm{~min}$ incubation at $38^{\circ} \mathrm{C}$ after thawing was shown by insemination doses with $6.0 \%$ glycerol. However, no significant relationship was found between motility III and glycerol concentration. Because of this fact it cannot be stated that $6.0 \%$ glycerol concentration in French diluent is the best for sperm progressive motility $2 \mathrm{~h}$ after thawing. The result is probably not only affected by the glycerol concentration but also by other factors. Cristanelli et al. (1985) determined the best concentration as $4.0 \%$ glycerol after a 90 min incubation of thawed insemination doses. However, this concentration was the highest of those investigated in this study. Our result and the outcome of Cristanelli et al. (1985) contradict the new publication by Marcias Garcia et al. (2012), who described the toxic effect of glycerol on sperm at a concentration $\geq 3.5 \%$ and recommended not to use concentrations higher than $2.5 \%$ glycerol in the freezing protocol of stallion sperm. The question is what role does the concentration of glycerol in the diluent play in the survival of sperm after thawing, because no significant correlation $(P>0.5)$ was found when comparing the concentration of glycerol in the diluent and sperm motility after $120 \mathrm{~min}$ incubation at $38^{\circ} \mathrm{C}$.

This study has brought further information for equine ejaculate freezing and has expanded the number of studies that prefer to use a higher percentage of glycerol in the diluent. At the same time, the study showed the need to investigate the effect of diluents and cryopreservation on sperm not only immediately after thawing but also during the subsequent incubation and their influence on sperm fertilization itself.

\section{Acknowledgement}

This project was supported by the Internal Grant Agency of the Univerity of Veterinary and Pharmaceutical Sciences (IGA 105/2016/FVL).

\section{References}

Alvarenga MA, Papa FO, Landim-Alvarenga FC, Medeiros ASL 2005: Amides as cryoprotectants for freezing stallion semen: a review. Anim Reprod Sci 89: 105-113

Alvarez C, Gil L, Gonzalez N, Olaciregui M, Luno V 2014: Equine sperm post-thaw evaluation after the addition of different cryoprotectants added to INRA $96^{\circledR}$ extender. Cryobiology 69: 144-148

Ball BA, Vo A 2001: Osmotic tolerance of equine spermatozoa and the effects of soluble cryoprotectants on equine sperm motility, viability, and mitochondrial membrane potential. J Andrology 22: 1061-1069

Barker CAV, Gandier JCC 1957: Pregnancy in a mare resulted from frozen epididymal spermatozoa. Cand J Comp Med Vet Sci 21: 47-51

Burns PJ, Reasner DS 1995: Computerized analysis of sperm motion: effects of glycerol concentration on the cryopreservation of equine spermatozoa. J Eq Vet Sci 15: 377-380

Chenier T, Merkies K, Leibo S, Plante C, Johnson W 1998: Evaluation of cryoprotective agents for use in the cryopreservation of equine spermatozoa. Proc American Association of Equine Practitioners - Annual Convention, Baltimore, USA pp 5-7

Cochran JD, Amann RP, Froman DP, Pickett BW 1984: Effects of centrifugation, glycerol level, cooling to $5^{\circ} \mathrm{C}$, freezing rate and thawing rate on the post-thaw motility of equine sperm. Theriogenology 22: 25-38

Cristanelli MJ, Amann RP, Squires EL, Pickett BW 1985: Effects of egg yolk and glycerol levels in lactose-EDTAegg yolk extender and of freezing rate on the motility of frozen-thawed stallion spermatozoa. Theriogenology 24: $681-686$

Demick DS, Voss JL, Pickett BW 1976: Effect of cooling, storage with glycerolization and spermatozoa number on equine fertility. J Animal Sci 43: 633-637

Fayrer-Hosken R, Abreu-Barbarosa C, Heusner G, Jones L 2008: Cryopreservation of stallion spermatozoa with INRA96 and glycerol. J Eq Vet Sci 11: 672-676

Ferreira HN, Johnson AEM, Coutinho da Silva MA 2008: Effect of freezing extenders and cryoprotectants on sperm motility and viability post-thaw. Anim reprod Sci 107: 319-320

Futino DO, Mendes MC, Matos WN, Mondadori RG, Lucci CM 2010: Glycerol, methyl-formamide and diethylformamide in canine semen cryopreservation. Reprod Domest Anim 45: 214-220

Gomes GM, Jacob JCF, Medeiros ASL, Papa FO, Alvarenga MA 2002: Improvement of stallion spermatozoa preservation with alternative cryoprotectants for the Mangalarga Marchador breed. Theriogenology 58: $277-279$ 
Hoffmann N, Morandini C, Sieme H 2010: Determination of the optimal concentration of cryoprotectant agent for freezing stallion spermatozoa. Anim Reprod Sci 121S: S160-S162

Hoffmann N, Oldenhof H, Morandini C, Rohn K, Sieme H 2011: Optimal concentrations of cryoprotective agents for semen from stallions that are classified "good" or "poor" for freezing. Anim Reprod Sci 125: 112-118

Marcias Garcia B, Ortega Ferrusola C, Aparicio IM, Miro-Moran A, Morillo Rodriguez A, Gallardo Bolanos JM, Gonzalez Fernandez L, Balao da Silva CM, Rodriguez Martinez H, Tapia JA, Pena FJ 2012: Toxicity of glycerol for the stallion spermatozoa: Effects on membrane integrity and cytoskeleton, lipid peroxidation and mitochondrial membrane potential. Theriogenology 77: 1280-1289

Mazur P, Leibo SP, Seidel Jr. GE 2008: Cryopreservation of the germplasm of animals used in biological and medical research: importance, impact, status, and future directions (2008). Biol Reprod 78: 2-12

Melo CM, Zahn FS, Martin I, Orlandi C, Dell'Aqua JA, Alvarenga MA, Papa FO 2007: Influence of semen storage and cryoprotectant on post-thaw viability and fertility of stallion spermatozoa. J Eq Vet Sci 27: 171-175

Moffett P, Fors G, Graham JK 2016: Cryopreservation of stallion sperm in freezing diluents containing glycerol alone or a combination of cryoprotectants. J Equine Vet Sci 43: S69

Moore AI, Squires EL, Bruemmer JE, Graham JK 2006: Effect of cooling rate and cryoprotectant on the cryosurvival of equine spermatozoa. J Equine Vet Sci 26: 215-217

Palmer E 1984: Factors affecting stallion semen survival and fertility. In: Proceedings of the $10^{\text {th }}$ International Congress on Animal Reproduction, AI, USA: 377-378

Polge C, Smith AU, Parkes AS 1949: Revival of spermatozoa after vitrification and dehydration at low temperatures. Nature (Lond.) 164: 666

Pucci B, Papa FO, Sanches FM, Nobrega JN, Crespilho AM, Pasquini DF, Campos JR, Melo CM, DellAqua CPF, Alvarenga MA, DellAqua Jr JA 2008: Effect of sperm and cryoprotectant concentration on equine semen freezability. Anim Reprod Sci 107: 342-343

Squires EL, Keith SL, Graham JK 2004: Evaluation of alternative cryoprotectants for preserving stallion spermatozoa. Theriogenology 62: 1056-1065

Swelum AA, Mansour HA, Elsayed AA, Amer HA 2011: Comparing ethylene glycol with glycerol for cryopreservation of buffalo bull semen in egg-yolk containing extenders. Theriogenology 76: 833-842

Vidament M, Yvon JM, Couty I, Arnaud G, Nguekam-Feugang J, Noue P, Cottron S, Le Tellier S, Noel F, Palmer E, Magistrini M 2001: Advances in cryopreservation of stallion semen in modified INRA82. Anim Reprod Sci 68: 201-218

Vidament M, Daire C, Yvon JM, Doligez P, Bruneau B, Magistrini M 2002: Motility and fertility of stallion semen frozen with glycerol and/or dimethyl foramide. Theriogenology 58: 249-251

Woods EJ, Benson JD, Agca Y, Critser JK 2004: Fundamental cryobiology of reproductive cells and tissues. Cryobiology 48: 146-156

Wu Z, Zheng X, Luo Y, Huo F, Dong H, Zhang G, Yu W, Tian F, He L, Chen J 2015: Cryopreservation of stallion spermatozoa using different cryoprotectants and combinations of cryoprotectants. Anim Reprod Sci 163: 75-81 